\title{
Clinical and Technological Dependence Characteristics on a Series of Brazilian Cases with Infantile Onset Pompe Disease in Enzyme Replacement Therapy
}

\author{
Paula De Almeida Thomazinho' ${ }^{1}$, Eliana Pelissari², Regina Célia Beltrão Duarte ${ }^{3}$, \\ Carolina Fishinger Moura De Souza ${ }^{4}$, Heloíse Helena Siqueira Borges ${ }^{5}$, \\ Maria Da Glória Cruvinel Horta ${ }^{6}$, Liane De Rosso Giuliani7 ${ }^{7}$, Ana Maria Martins ${ }^{8}$, Lilian Stewart ${ }^{9}$, \\ Dafne Dain Gandelman Horovitz ${ }^{10}$, Juan Clinton Llerena ${ }^{10}$
}

\author{
${ }^{1}$ Motor Physical Therapy Unit, Fernandes Figueira National Institute/FIOCRUZ, Rio de Janeiro, Brazil \\ ${ }^{2}$ Clinical Medical Unit, Dr. Jeser Amarante Faria Children's Hospital, Joinville, Brazil \\ ${ }^{3}$ Pediatric Neurology Unit, Santa Casa de Misericórdia do Pará Foundation, Belém, Brazil \\ ${ }^{4}$ Sciences Medical Genetics Unit, Service of Information on Inborn Errors of Metabolism, Hospital de Clínicas de Porto Alegre, \\ Porto Alegre, Brazil \\ ${ }^{5}$ Clinical Medical Unit, University of Cuiabá UNIC, Cuiabá, Brazil \\ ${ }^{6}$ Santa Casa de Belo Horizonte, Belo Horizonte, Brazil \\ ${ }^{7}$ Genetics Unit, Federal University of Mato Grosso do Sul, Campo Grande, Brazil \\ ${ }^{8}$ Inborn Errors of Metabolism and Genetics Unit, Federal University of São Paulo, UNIFESP, São Paulo, Brazil \\ ${ }^{9}$ Pediatric Intensive Care Unit, State Institute of Cardiology of Rio de Janeiro, IECAC, Rio de Janeiro, Brazil \\ ${ }^{10}$ Medical Genetics Unit, Fernandes Figueira National Institute of Women, Children and Adolescent Health/FIOCRUZ, \\ Rio de Janeiro, Brasil \\ Email: paula.thomazinho@iff.fiocruz.br
}

How to cite this paper: De Almeida Thomazinho, P., Pelissari, E., Duarte, R.C.B., De Souza, C.F.M., Borges, H.H.S., Da Glória Cruvinel Horta, M., De Rosso Giuliani, L., Martins, A.M., Stewart, L., Horovitz, D.D.G. and Llerena, J.C. (2019) Clinical and Technological Dependence Characteristics on a Series of Brazilian Cases with Infantile Onset Pompe Disease in Enzyme Replacement Therapy. Open Journal of Clinical Diagnostics, 9, 16-32. https://doi.org/10.4236/ojcd.2019.91002

Received: February 7, 2019

Accepted: March 19, 2019

Published: March 22, 2019

\begin{abstract}
Pompe disease (PD) is a rare inborn error of metabolism due to an abnormal acid alpha-glucosidase (GAA) activity that comprises glycogen breakdown mainly in the lysosomes. Since the introduction of enzyme replacement therapy (ERT), with recombinant human GAA for the early onset PD patient, a relevant field of clinical research due to the benefits regarding survival rate has been widely documented worldwide. Objective: To describe the clinical characteristics and the ERT effects in a series of Brazilian patients with infantile onset PD (IOPD) under ERT. Methods: Brazilian patients diagnosed with IOPD under ERT were recruited through their physicians participating in the International Pompe Disease Registry from 2009 to 2017. Data were collected by an online survey. Results: 10 IOPD patients were identified through the survey with a death rate of $30 \%$ and technology dependency rate reported as
\end{abstract}


Copyright $\odot 2019$ by author(s) and Scientific Research Publishing Inc. This work is licensed under the Creative Commons Attribution International License (CC BY 4.0).

http://creativecommons.org/licenses/by/4.0/

Open Access
$80 \%$ (motor, respiratory or nutritional fields) of the patients. After the third year of ERT, motor disabilities were lost in $50 \%$ of ambulated patients. The overall characteristics were similar to international studies. Conclusion: Despite ERT benefits in cardiac involvement, motor disabilities seem to be much more compromised in IOPD patients, with high technology dependence, especially after three years of age.

\section{Keywords}

Motor Development, Child Disability, Glycogen Storage Disease Type II, Enzyme Replacement Therapy

\section{Introduction}

Pompe disease (DP) or glycogenosis type II is a rare, progressive, autosomal recessive disorder of glycogen metabolism caused by a deficiency of the lysosomal enzyme acid alpha-glucosidase (GAA, 3.2.1.20) [1] [2]. The multi-systemic lysosomal storage of glycogen and the release of other hydrolases into the cytoplasm cause cell death and autophagic pathway disorders, especially in the smooth, striated and cardiac muscles, nerve tissue and liver [3] [4] [5].

Infantile onset Pompe disease (IOPD) is the most severe and rare form of the disease, with an estimated incidence of 1:138,000 live births. With residual levels of enzymatic activity $(<1 \%)$, the clinical manifestations of IOPD can be identified in the first months of life [6]. Major symptoms include hypotonia and muscular weakness, delayed motor development, massive hypertrophic cardiomegaly, macroglossia and variable degrees of hepatomegaly with elevated muscle enzymes; difficult deglutition, causing malnutrition, recurrent aspiration pneumonia and respiratory tract infections are common comorbidities found in IOPD patients [7] [8] [9] [10].

Dramatic prognostic changes have been documented in IOPD since the approval of enzyme replacement therapy (ERT) treatment with recombinant human GAA enzyme (rhGAA) such as in 2007 [1]. An increase in life expectancy is now well documented, as a result, of a better efficacy of ERT towards the cardiac muscle; and gain of motor functions due to the effect of ERT in skeletal muscles [6]. However, new clinical comorbidities have emerged from cohorts of IOPD in the follow-up ERT studies characterizing for some authors as a new IOPD phenotype, including as recently documented white matter anomalies affecting neuropsychological development [11] [12] [13].

Only two cases of IOPD treated with ERT have been published in Brazil [14] [15]. A retrospective series of IOPD cases was presented in 2009 [16] with the objective of describing genotypes in IOPD and late onset Pompe Brazilian patients, however, not addressing the effects of treatment or clinical details. Therefore, considering that this issue must be explored, the presentation of a series of Pompe with systematic follow-up of Brazilian patients with IOPD under 
ERT plays a fundamental role in the planning of care programs.

This study aimed to describe the clinical and technological dependence characteristics in a series of Brazilian patients with IOPD treated with ERT, and discuss our findings with similar studies of IOPD patients treated in other countries.

\section{Methods}

This is a descriptive study of IOPD patients under ERT in Brazil, whose physicians in charge were identified through the International Registry of PD, and completed the ethical formalities.

We included all patients with IOPD diagnosis with low GAA activity in fibroblasts (gold standard) or in filter paper, or with the presence of two GAA pathogenicmutations; and treated with ERT in the 2009-2017 period, using rhGAA standard dose (20 mg/kg every two weeks) [7] [9]. No exclusion criteria were applied.

The clinical characteristics, motor profile and technological dependence were obtained from patient's medical records of all subjects. The following data were extracted by the localphysicians in an online Google form questionnaire created for this proposal including age at onset of symptoms, age at diagnosis, age at start of ERT, age at death or current age, clinical problems, surgical interventions, or procedures related to disease or to ERT, CRIM-status, genotype studies, the best motor milestone ever achieved and for the current or last motor status (i.e. no sitting, sitting without support, free walking, running) and other treatment modalities. Cardiac data were not collected, due to difficulties in comparing the results of the examinations performed and interpreted by different cardiologists. Data were analyzed with Microsoft Excel $^{\circledR} 2010$.

Independent Ethics Committees, from the National Fernandes Figueira Institute (CEP/IFF/Fiocruz) and other enrolled centers, approved protocols and consent forms obtained from the children's parents.

A literature review was performed in PubMed, Bireme, EMBASE and COCHRANE, from 2006 onwards, focusing on clinical studies for IOPD to compare our results. The predefined search was designed for maximal retrieval using two strategies: indexing terms (or medical subject heading) and free-text searching. The terms used were: "Glycogen Storage Disease Type II/therapy"; "infantile Pompe disease", "Pompe disease", "classic infantile pompe disease"; "enzyme replacement therapy"; combined with each other by connectors AND, OR and limited by age (child). Duplicated original articles were excluded and for the papers referring to the same group of patients were considered the most recent publication. Manual searches on the references of the selected articles were done too.

\section{Results}

Nine treatment centers adhered to the survey, with a total of 10 patients with IOPD under ERT in the sample, with $70 \%(n=7)$ males and $30 \%(n=3)$ fe- 
males. Two further cases of deceased patients were excluded, since ERT treatment was not installed in time. Table 1 shows the patients characteristics and genotypes.

Table 1. Demographic and clinical profile of children with Pompe disease treated with ERT in Brazil (2009-2017).

\begin{tabular}{|c|c|c|c|c|c|c|c|c|c|c|}
\hline \multirow{2}{*}{\multicolumn{2}{|c|}{ N Gender }} & \multirow{2}{*}{$\begin{array}{c}\text { Initial } \\
\text { Symptoms }\end{array}$} & \multirow{2}{*}{$\begin{array}{l}\text { Age at } \\
\text { diagnosis } \\
\text { (months) }\end{array}$} & \multirow{2}{*}{$\begin{array}{c}\text { Age at } \\
\text { onset } \\
\text { of ERT } \\
\text { (months) }\end{array}$} & \multicolumn{2}{|c|}{ GAA mutations } & \multirow{2}{*}{$\begin{array}{c}\text { Previous } \\
\text { family } \\
\text { history }\end{array}$} & \multirow{2}{*}{$\begin{array}{l}\text { CRIM } \\
\text { Status* }^{*}\end{array}$} & \multirow{2}{*}{$\begin{array}{l}\text { Intercurrences } \\
\text { and Comorbidities }\end{array}$} & \multirow{2}{*}{$\begin{array}{c}\text { Death/ } \\
\text { Current } \\
\text { age }^{* *}\end{array}$} \\
\hline & & & & & Allele 1 & Allele 2 & & & & \\
\hline 1 & $\mathrm{~F}$ & $\mathrm{HC}, \mathrm{MDI}$ & 2 & 2 & $\begin{array}{c}\text { c. } 2560 \mathrm{C}>\mathrm{T} \\
\text { p.R854X }\end{array}$ & $\begin{array}{c}\text { c. } 2481+ \\
102 \_2646+31 \mathrm{del}\end{array}$ & Yes & Positive & $\begin{array}{c}\text { PMT, PNM, } \\
\text { right tibia fracture } \\
\text { osteopenia, visual and } \\
\text { hearing impairment; } \\
\text { distended bladder; } \\
\text { kyphoscoliosis, } \\
\text { palpebral ptosis }\end{array}$ & $8 \mathrm{y} 3 \mathrm{~m}$ \\
\hline 2 & $\mathrm{~F}$ & $\begin{array}{l}\text { macroglossia, } \\
\text { hypotonia } \\
\text { and MW, } \\
\text { SDI, MDI, RI }\end{array}$ & 3 & 4 & $\begin{array}{l}\text { c. } 1504 \mathrm{~A}>\mathrm{G} \\
\text { p.Met502Val }\end{array}$ & $\begin{array}{c}\text { Normal } \\
\text { (MLPA }^{\#} \\
\text { not performed })\end{array}$ & No & Positive & $\begin{array}{c}\text { coxofemoral } \\
\text { dysplasia; lordosis } \\
\text { and scoliosis; hidde } \\
\text { bifid spine; PNM }\end{array}$ & $6 y$ \\
\hline 3 & $\mathrm{M}$ & $\begin{array}{l}\text { HC, macroglossia, } \\
\text { hypotonia and } \\
\text { MW, SDI, MDI, } \\
\text { RI, hepatomegaly }\end{array}$ & 36 & 37 & $\begin{array}{c}\text { c.1408_1410 del } \\
\text { p.N470del }\end{array}$ & $\begin{array}{c}\text { c.1556T >C; } \\
\text { p.M519T }\end{array}$ & No & Positive & $\begin{array}{c}\text { PNM; } \\
\text { kyphoscoliosis }\end{array}$ & $5 y 6 m$ \\
\hline 4 & $\mathrm{~F}$ & $\begin{array}{l}\text { HC, macroglossia, } \\
\text { hypotonia and MW, } \\
\text { SDI, MDI, RI, } \\
\text { hepatomegaly }\end{array}$ & 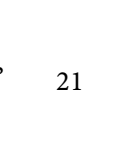 & 23 & c. $692+2 \mathrm{~T}>\mathrm{C}$ & c. $692+2 \mathrm{~T}>\mathrm{C}$ & No & Positive & PNM & $4 y 3 m$ \\
\hline 5 & $\mathrm{M}$ & $\begin{array}{l}\text { HC, macroglossia, } \\
\text { hypotonia and MW, } \\
\text { SDI, MDI, RI }\end{array}$ & 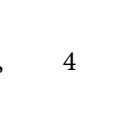 & 5 & $\begin{array}{c}\text { c. } 2560 \mathrm{C}>\mathrm{T} \\
\text { p.R854 }\end{array}$ & $\begin{array}{c}\text { c.2501_2502 } \\
\text { del CA } \\
\text { p.T834 Rfs49 }\end{array}$ & No & Negative & $\begin{array}{l}\text { CA, cerebral atrophy, } \\
\text { PNM, convulsions, } \\
\text { cognitive impairment }\end{array}$ & $3 y 7 m$ \\
\hline 6 & $\mathrm{M}$ & $\begin{array}{l}\text { HC, macroglossia, } \\
\text { SDI, MDI, RI }\end{array}$ & 5 & 7 & $\begin{array}{l}\text { c. } 1941 \mathrm{C}>\mathrm{G} \\
\text { p.C647W }\end{array}$ & $\begin{array}{c}\text { c.2501_2502 } \\
\text { del CA } \\
\text { p.T834 Rfs49 }\end{array}$ & No & Positive $^{+}$ & CA, PNM, scoliosis & 3y $1 \mathrm{~m}$ \\
\hline 7 & $\mathrm{M}$ & $\begin{array}{l}\text { HC, macroglossia, } \\
\text { hypotonia and } \\
\text { MW, MDI, RI, } \\
\text { hepatomegaly }\end{array}$ & 8 & 8 & $\begin{array}{c}\text { c. } 2560 \mathrm{C}>\mathrm{T} \\
\text { p.R854 }\end{array}$ & $\begin{array}{c}\text { c. } 236 \_246 \text { del11bp } \\
\text { p.P79Rfs }{ }^{\star} 13\end{array}$ & No & Positive & $\mathrm{CA}$ & $\dagger 2 \mathrm{y} 6 \mathrm{~m}$ \\
\hline 8 & $\mathrm{M}$ & $\begin{array}{l}\text { HC, macroglossia, } \\
\text { hypotonia and } \\
\text { MW, MDI, } \\
\text { hepatomegaly }\end{array}$ & 1 & 4 & $\begin{array}{c}\text { c.1941C > G } \\
\text { (p.Cys647Trp) }\end{array}$ & $\begin{array}{c}\text { c. } 1941 \mathrm{C}>\mathrm{G} \\
\text { (p.Cys647Trp) }\end{array}$ & No & Positive & PNM, kyphoscoliosis & $2 y$ \\
\hline 9 & $\mathrm{M}$ & $\begin{array}{l}\text { HC, hypotonia } \\
\text { and MW, MDI, RI, } \\
\text { hepatomegaly }\end{array}$ & 4 & 5 & $\begin{array}{c}\text { C } 2560 \mathrm{C}>\mathrm{T} \\
\text { p.R854 }\end{array}$ & $\begin{array}{c}\text { C } 2560 \mathrm{C}>\mathrm{T} \\
\text { p.R854 }\end{array}$ & Yes & Negative & convulsions, $\mathrm{PNM}$ & $\dagger 1 \mathrm{y} 1 \mathrm{~m}$ \\
\hline 10 & $\mathrm{M}$ & $\begin{array}{l}\text { HC, macroglossia, } \\
\text { hypotonia and } \\
\text { MW, SDI, MDI }\end{array}$ & 5 & 8 & $\begin{array}{l}\text { c. } 2560 \mathrm{C}>\mathrm{T} \\
(\mathrm{p} . \operatorname{Arg} 854)\end{array}$ & $\begin{array}{c}\text { c.1912G > T } \\
\text { (p.Gly638Trp) }\end{array}$ & No & Positive $^{+}$ & PMT, PNA & $\dagger 9 \mathrm{~m}$ \\
\hline
\end{tabular}

${ }^{*}$ Byprediction or Western Blot; ${ }^{* *}$ The age of the patients was calculated until the end of the data collection (January 2017). "MLPA: Multiplex Ligand Probe Amplification; ${ }^{+}$CRIM status was considered positive based on one of the alleles previously identified in the Hispanic population. HC: Hypertrophic Cardiomyopathy; MW: Muscular Weakness; PNA: Perinatal Asphyxia; SDI: Suction/Deglutition Impairment; MDI: Motor Development Impairment; RI: Respiratory Insufficiency; CA: Cardiorespiratory Arrest; PMT: Prematurity; PNM: Pneumonia; $\uparrow$ : death; $\varnothing$ : absent. 
In our series, the first clinical symptom was motor-related, with delayed motor development in $100 \%$ of patients. Hypertrophic cardiomyopathy (90\%), hypotonia $(80 \%)$, muscle weakness $(80 \%)$ and macroglossia $(80 \%)$ were other major complaints.

The mean age of diagnosis was 8.9 months ( 1 - 36 months), with a median of 4.5 months. It was still slightly lower than the series of 21 cases of Brazilian children with IOPD (4.5 months vs. 5 months) [16]. Early signs of IOPD were observed before the age of five months in $70 \%$ of the series. Regarding ERT, only $10 \%$ of children (1:10) started treatment before three months of age, with a median age of 5.5 months. The mean interval between diagnosis and ERT onset was 1.3 months (0 - 3 months). Both the median age at diagnosis and the ERT onset were equivalent to the majority studies conducted in developed countries.

Two patients with a diagnosis older than 12 months were kept in the sample because they had a clinical condition compatible with the typical form of IOPD, including hypertrophic cardiomyopathy (cases 3 and 4). Another case classified as atypical IOPD (case 2), without cardiomyopathy and heterozygote to one GAA mutation only, was also maintained due to early onset of symptoms and low GAA activity in fibroblast cultures $(3.50 \mathrm{nmoles} / \mathrm{hr} / \mathrm{mg}$ prot), the latter considered as "gold standard" for Pompe diagnosis. It should be noted that, in the latter case, the genomic study is still incomplete as to be classified as true heterozygote for the GAA gene and IOPD case.

All genotypes from our patients were previously described in the literature; with the exception of two patients were no previous records of one of the mutations (cases 6 and 10). Sixty percent of cases (6:10) were compound heterozygotes. The c.2560C $>\mathrm{T}$ nonsense mutation, associated with high disease severity, was found more frequently, in $50 \%$ of the sample (5:10).

CRIM+ status was identified in $80 \%$ of patients. One of the CRIM-cases (case 5) performed immunomodulation with rituximab (monoclonal antibody) and methotrexate (immunosuppressive) to prevent anti-rhGAA antibodies production [17] [18].

The mean treatment time until the end of the data collection was 2.75 years, with a median of 2.25 years ( 0 to 8 years). The mortality rate found in the study period was $30 \%$ (3:10), with a mean age of death of 1.44 years (0.75 - 2.5 years). Pneumonia was the most prevalent cause of death. The mean duration of ERT treatment before death was 11 months ( $1-24$ months), with a median of 8 months. The mean age of the patients with IOPD still under ERT at the end of the data collection $(n=7)$ was 4.71 years $(2.03-8.31$ years).

The ventilatory support-free survival is an important outcome in IOPD under ERT study. At diagnosis, $70 \%$ of the children $(n=7)$ already had signs of respiratory insufficiency although they still maintained oral feeding. Deterioration of respiratory function during treatment was observed in $60 \%$ of the cases, requiring tracheostomy (6:10) and dependence on continuous ventilatory assistance (6:10) (Table 2). 
Table 2. Health conditions, technological dependence and motor function of children with Infantile Pompe Disease in ERT in Brazil.

\begin{tabular}{|c|c|c|c|c|c|}
\hline \multirow{2}{*}{$\mathrm{N}$} & \multicolumn{3}{|c|}{ Recent/Current Health Condition } & \multicolumn{2}{|c|}{ Motor Function } \\
\hline & Treatment & Respiratory & Dietary & Maximum acquisition achieved & Current/Recent \\
\hline 1 & Hospitalized & TCT, MV & GTT & Walking without support & WC \\
\hline 2 & Outpatient & Spont. Resp Ambient air & Oral & Walking without support & Walking \\
\hline 3 & Home care & TCT, MV & GTT & Walking with support & WC \\
\hline 4 & Hospitalized & TCT, MV & GTT & BR & $\mathrm{BR}$ \\
\hline 5 & Home care & TCT, MV & GTT & BR & $\mathrm{BR}$ \\
\hline 6 & Home care & TCT, MV & GTT & $\mathrm{HC}$ & BR \\
\hline 7 & $\dagger$ & TCT, night MV & GTT & Standing without support & $\dagger \mathrm{BR}$ \\
\hline 8 & Outpatient & Spont. Resp Ambient air & Oral & Walking & Walking \\
\hline 9 & $\dagger$ & MV & GTT & $\mathrm{HC}$ & $\dagger \mathrm{HC}$ \\
\hline 10 & $\dagger$ & Spont. Resp Ambient air & NGT & $\mathrm{HC}$ & $\dagger \mathrm{HC}$ \\
\hline
\end{tabular}

N: number of patient in the study, TCT: tracheostomy, MV: mechanical ventilation; GTT: gastrostomy; NGT: nasogastric tube, HC: head control, BR: bedridden; WC: wheelchair, $\uparrow$ : death.

Another critical clinical outcome for IOPD under ERT is related to motor function. Little or no motor improvement was observed in half of the sample, with an important restriction of mobility activity. Free or supported gait was observed in $40 \%$ (4:10) of the children, and 50\% of these children (2:4) lost their capacity throughout the development of the disease; and, at the end of the study a total of $50 \%$ of patients were on wheelchair or bedridden (5:10). The mean age of gait loss was 4.25 years ( 3.0 - 5.5 years).

Table 2 shows the profile of health conditions, technological dependence and motor function of our series; and Figure 1, the free survival of ventilatory assistance concerning the best motor function achieved during the treatment.

The atypical genotypic profile of patient 2 compared to others in the sample may justify the best clinical evolution, although there were concomitant malformations (acetabular dysplasia and hidden bifid spine).

The GAA antibodies investigation was not systematically performed in all patients on ERT, which did not allowed any correlation of this factor with the motor or functional outcomes in our series. As reported in the literature, IOPD patients with CRIM+ tend to have low anti-rhGAA antibodies albeit under the influence of the exposure to rhGAA because they are innately immunologically sensitized [6] [19] [20].

Among related complications in our series were scoliosis (50\% of cases, 5:10), ankle joint deformity $(30 \% ; 3: 10)$, fracture and osteopenia, palpebral ptosis, distended bladder and visual and hearing impairment (10\%, 1:10). Pneumonia was the most prevalent intercurrence $(80 \%, 8: 10)$. Other complications recognized in IOPD, such as nasal speech and gastroesophageal reflux [11] [21] [22] were not observed in this sample. 


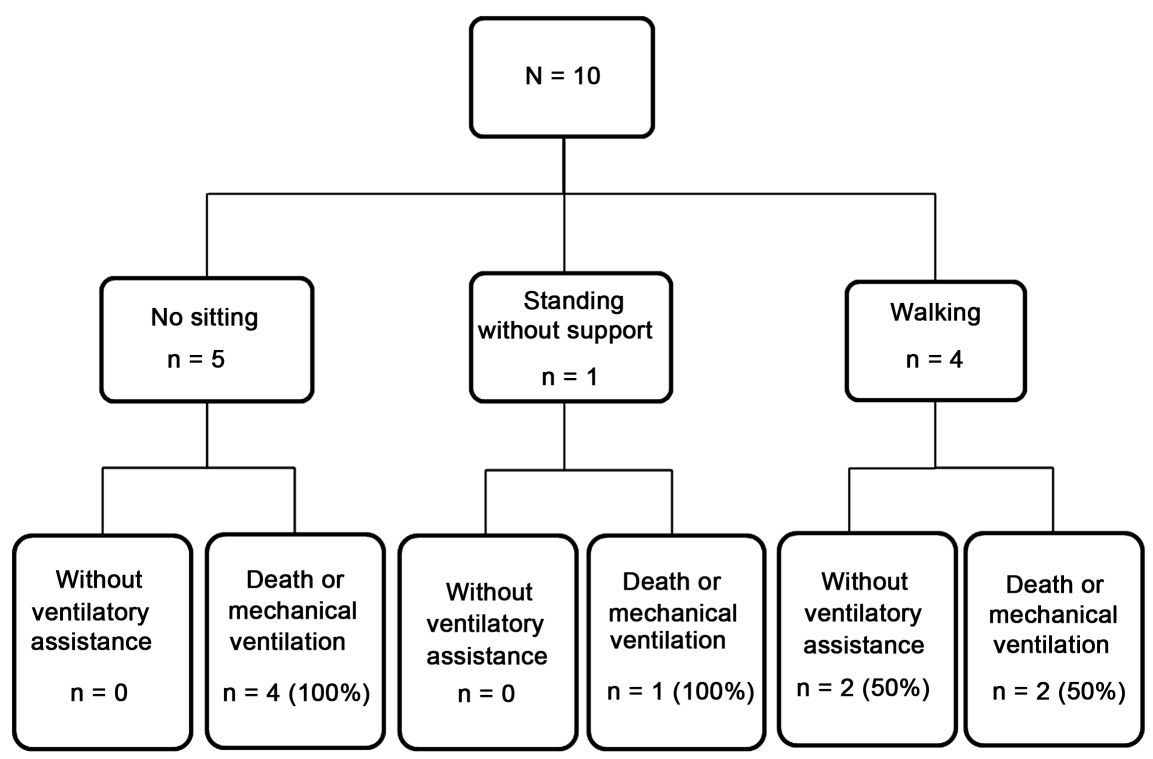

Figure 1. Ventilatory assistance outcome concerning the best motor acquisition achieved in Brazilian children with IOPD in ERT.

The technological dependence found in the sample was high. Eighty percent of the children needed some support for feeding, breathing or mobility; $60 \%$ underwent tracheostomy and 70\% gastrostomy.

\section{Discussion}

No publications were found regarding the aspects of morbidity and technological dependence of patients with IOPD treated with rhGAA in Brazil and fewer long-term follow-up studies outside clinical trials on the long-term efficacy of ERT [2]-[30]. Thus, we sought to compile the information from a series of Brazilian cases of IOPD patients under ERT treatment with rhGAA (Myozyme ${ }^{\oplus}$ ) between 2009 and 2017.

The sample size is a difficulty in any study of rare diseases, associated to a high morbimortality such as IOPD. Furthermore, the lack of knowledge of this disease by health professionals also favors underdiagnoses. The complexity of multi-professional care necessary in IOPD requires a coordinating center for the clinical management of these patients [7] [9] [31]. In Brazil, considering its territorial extension and the lack of a coordinating center as a limiting factor hampers research in this population. This report sought to overcome these barriers and to report information on functional repercussions in IOPD. The studied sample showed severe affected IOPD patients, with clinical and demographic characteristics equivalent to those evidenced by international studies (Table 3 ).

The high prevalence of muscle hypotonia, a clinical hallmark in IOPD as an early clinical sign, is also common among similar studies [25] [29] [30] [32]. The degree of muscle damage prior to the initiation of ERT treatment is reported in the literature as one of the important prognostic factors, commonly assessed by muscle biopsy [6] [33] [34] [35]. However, few centers performed it because it is 
Table 3. Comparison of clinical and epidemiological characteristics of children with classic IOPD among international studies.

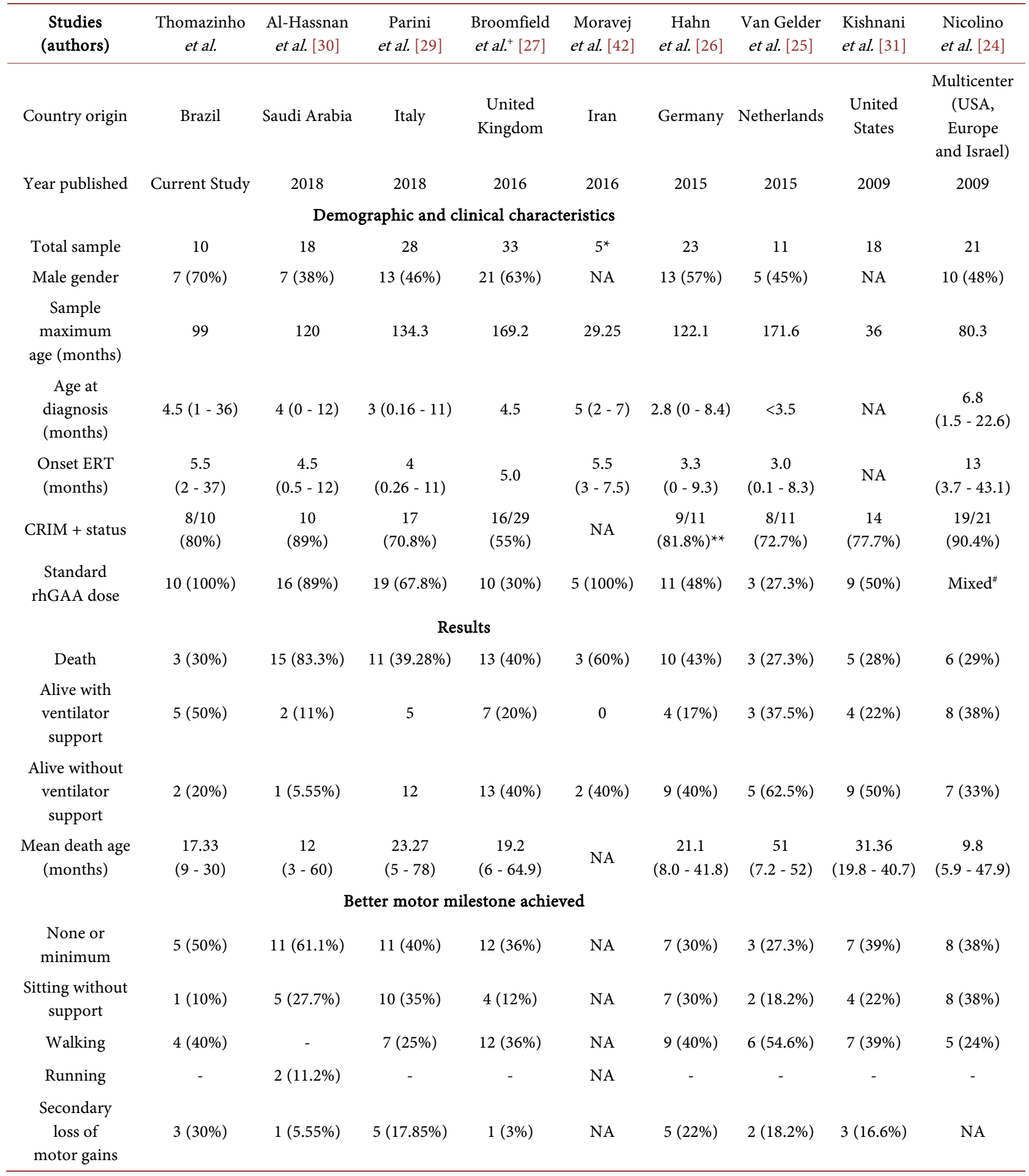

NA: Not available. Data are shown in absolute values or by the median, with percentage values or amplitude in parentheses. ${ }^{+}$Broomfield et al. (2016) study is an update Chakrapani et al. (2010) study. ${ }^{*}$ The sample included in the study a patient with death who had not received ERT treatment. For this analysis, the calculations were redone with the exclusion of this case. ${ }^{* *}$ In this study, only 11 patients (47.82\%) of the sample had an established CRIM status, namely, 9 with CRIM+ and 2 with CRIM-. Thus, CRIM+ status was predominant among the patients evaluated, representing $81.81 \%$ of the cases identified. ${ }^{* * *}$ CRIM status established in only $25 \%$ of the sample of this survey in children of the United Kingdom. "Patients started ERT at a standard dose of 20 $\mathrm{mg} / \mathrm{kg}$ every two weeks. After week 26 of treatment, dose increase was made available to patients with deteriorated clinical condition compared to the baseline clinical status. ${ }^{\#}$ Only half of the sample $(\mathrm{n}=10)$ was age compatible with gait gain $(>1$ year), and this milestone was found in $40 \%$ of the children with IOPD studied in this age group $(\mathrm{n}=4)$. 
an invasive exam, have difficulties of performing and variabilities of results. Recently, MRI has been used as a non-invasive method to evaluate the muscle status in IOPD prior ERT and as a treatment follow-up [36] [37]. However, no specific instrument quantifies the degree of muscular hypotonia that could serve as a noninvasive measure to assess initial muscle damage especially in infants.

Overall, most published studies, including Brazilian patients, indicates satisfactory motor development after the ERT onset in $40 \%$ of children with IOPD, up to the first three years of life [15] [25] [26] [27] [31].

Several mutations in the GAA gene have already been described for PD patients; including the Brazilian population. The most commonly found mutation in our study was the non-sense c.2560C $>\mathrm{T}$ that had already been reported previously as common among Brazilians IOPD patients (50\% vs. 33.33\%) [16]. However, the precise genotype-phenotype correlation based on mutation types remains very complex [33] [38]. Other genetic or environmental factors may contribute to phenotypic variability as described by several authors [39] [40] [41].

Regarding the CRIM status, CRIM-patients commonly develop high titers of antibodies against exogenous rhGAA, which eventually reduce the ERT effectiveness and make them more prone to motor function loss and rapid clinical decline, with a higher mortality rate [6] [23] [25]. Among the CRIM-cases, only the one who underwent immunomodulation therapy remained alive at the end of the study, despite the high technological dependency for life support required by the patient due to the pre-ERT complications.

The death rate was equivalent to that found in other international studies [25] [28] [30]; and lower than others [26] [27] [29] [30] [42]. The median duration of treatment before death was shown to be slightly higher than other studies (8 months vs. 5.52 months and 6.7 months) [27] [28]. The Kaplan Meier survival rate at the age of 3 years was between $64.2 \%$ to $72 \%$; and at 6 years of age from $49 \%$ to $58.8 \%$ [29] [31].

Many patients became dependent on ventilatory support with the disease progression. However, severe respiratory complications were rare. The need for ventilatory assistance for more than two weeks has been pointed out as poor prognostic factor for respiratory function [28]. With ERT, registers of the survival free for ventilatory support in the IOPD patients has unfortunately decreased with the progression of the disease, from $88.9 \%$ after 1 year, to $66.7 \%$ at 2 years and $49.4 \%$ at 3 years, according to the extension study within the series of patients of the original clinical trial with rhGAA [6].

The degree of respiratory impairment does not always appears to be related to the level of musculoskeletal weakness [43]; although, this is a poor prognosis predictor [44]. Unlike other neuromuscular disorders in which loss of walking ability precedes ventilatory failure, respiratory symptoms may manifest early in PD [1] [45] [46]. Studies in late onset PD showed heterogeneity in respiratory and locomotor systems involvement with no correlation between the locomotion capacity by the 6-minute walk test (6MWT) and the severity of respiratory im- 
pairment [43] [47].

Respiratory impairment can occur due to respiratory muscle hypotrophy associated to the involvement of the spinal moto neurons, in particular the phrenic moto neuron. As a consequence, contributes to a more pronounced diaphragmatic failure [34] [46] [48] [49], aggravating the thoracic cage dynamic kyphoscoliosis associated frequently to the Pompe phenotype which progressively decreases lung capacity [50]. The pathophysiology of respiratory insufficiency in neuromuscular diseases also includes alterations in central respiratory control, alveolar hypoventilation, paradoxical movement of the abdominal muscles, sleep apnea, atelectasis, hyper responsiveness of airways and recurrent pneumonia, and most importantly an abnormal and ineffectiveness of cough [51].

There was no discontinuation of ERT treatment in our patients during this study; so the effects of ERT cessation on respiratory function decline and mobility capacity was not considered as a major factor for a worsen health [52].

Regarding the motor function, mobility loss in IOPD is also described in other longitudinal studies of children with a good initial response to ERT [25] [26] [29] [53]. Thus, the identification of stability or improvement of motor condition should be considered as an extremely positive result, due to the markedly aggressive, progressive and unfavorable IOPD evolution, primarily due to the difficulties in providing adequate ERT to the skeletal musculature and/or initiating an early treatment [54].

The prevalence of other IOPD-associated complications, such as joint and spine deformities; osteopenia, palpebral ptosis, hearing loss due to cochlear (sensorineural) or conductive apparatus (conduction) was less frequent in our series compared to other reports [11] [22] [55]. This could be due to a shorter time of the disease evolution among our series; or a small number of cases in our study; or even, due to the difficulties of assessment of these parameters. Osteopenia is reported to be highly prevalent in IOPD $(>80 \%)$, including a significant correlation between proximal muscle strength, both in walking patients and wheelchair users [55] [56]. It can be observed as early as four months of age and is attributed to chronic immobilization and muscular weakness, even among patients with proper nutrition [32] [56]. Long-bone fractures in IOPD are also described in the literature [57]. Furthermore, the limitation of evaluating normal bone density by DEXA in this age group can be as well troublesome.

Joint deformities are observed in many genetic disorders, especially with impaired tone and muscle strength [29] [58] [59]. Ankle deformity in equine is common complication related to anterior leg muscular weakness frequently identified in IOPD [12]. Orthosis was used to maintain motion range and joint alignment in only $10 \%$ of our cases (33.3\% of identified joint deformities cases).

The low prevalence of scoliosis in IOPD may be due to a lack of awareness with the postural evaluation in this age group [50]. The prevalence here is similar to a study of children with late-onset PD [60], and higher than another (50\% vs. 33\%) [50]. Adequate postural alignment is vital for the maintenance of respiratory function, and patients must have been followed up for this alteration since 
the ERT onset, which reinforces the value of the multidisciplinary team in the care of these patients.

Concerning hearing impairment, the literature reports a prevalence of more than $90 \%$ among children with classic IOPD, with persistent hearing loss during ERT treatment, not correlated with the age of the patient [22] [61], which compared to our study, reflects probably underdiagnoses of this comorbidity.

The high technological dependence was observed as in other chronic conditions. The use of feeding support (nasogastric probe or gastrostomy feeding) was higher than that reported in another study of IOPD (80\% vs $40 \%$ ) [27], perhaps related to the differences between the death rate and the information about this technology use among described cases in referred study. It may also reflect the practices of early and preventive gastrostomy performed by Brazilian centers, in the face of severe deglutition disorder signs associated with the bulbar system involvement.

These results indicates the need for disease disclosure among Brazilian health professionals to improve the early diagnosis and treatment approach to achieve more favorable outcomes similar as appointed by other studies [62] [63].

Some important shortcomings were its retrospective nature and data ascertainment by independently institutions. However, the data compiled in this investigation about the current limitations of ERT in IOPD are essential to provide accurate advice to families.

\section{Conclusions}

Since the ERT implementation, systematic follow-up of treated PD cases has become essential and has been the focus of recent studies. Significant advances in the understanding of IOPD have been occurring continuously through care interdisciplinary collaboration for this condition [61] [64].

This study in the Brazilian population is very relevant for IOPD children health care and care line planning in the Unified Health System. The cases presented showed similarities with international studies and highlighted some of the difficulties in managing IOPD.

Longitudinal follow-up contributes to a better understanding the ERT effects on IOPD. The results allowed us to infer that, despite the progressive nature of IOPD, regardless of ERT, its clinical evolution is not homogeneous, as it is seen in other congenital neuromuscular disease. Motor functions appear to be very much impaired in IOPD, with a high dependence on technology, especially after three years of age. The chronicity profile of the disease and high therapeutic complexity identified, in addition to the necessary interventions/propaedeutic, requires the continuous monitoring of patients' evolution, especially regarding acquired motor patterns and other aspects of functionality that should be addressed in future research.

\section{Acknowledgements}

To Dr. PriyaKishnani, Dr. Deeksha Bali and colleagues at the Division of Medi- 
cal Genetics, Department of Pediatrics, Duke University Medical Center, Durham, North Carolina, who kindly performed the cross-reactive immunologic material test.

\section{Conflicts of Interest}

The authors declare no conflicts of interest regarding the publication of this paper. Dr. Llerena is a member of the Pompe Disease Advisory Board for Genzyme, A Sanofi Company.

\section{References}

[1] Kishnani, P.S., Amartino, H.M., Lindberg, C., Miller, T.M., Wilson, A., Keutzer, J., et al. (2014) Methods of Diagnosis of Patients with Pompe Disease: Data from the Pompe Registry. Molecular Genetics and Metabolism, 113, 84-91.

https://doi.org/10.1016/j.ymgme.2014.07.014

[2] Hahn, S.H., Kronn, D., Leslie, N.D., Pena, L.D.M., Tanpaiboon, P., Gambello, M.J., et al. (2018) Efficacy, Safety Profile, and Immunogenicity of Alglucosidase Alfa Produced at the 4,000-Liter Scale in US Children and Adolescents with Pompe Disease: ADVANCE, a Phase IV, Open-Label, Prospective Study. Genetics in Medicine, 20, 1284-1294. https://doi.org/10.1038/gim.2018.2

[3] Raben, N., Wong, A., Ralston, E. and Myerowitz, R. (2012) Autophagy and Mitochondria in Pompe Disease: Nothing Is So New as What Has Long Been Forgotten. American Journal of Medical Genetics Part C: Seminars in Medical Genetics, 160C, 13-21. https://doi.org/10.1002/ajmg.c.31317

[4] Raben, N., Ralston, E., Chien, Y.H., Baum, R., Schreiner, C., Hwu, W.L., Zaal, K.J. and Plotz, P.H. (2010) Differences in the Predominance of Lysosomal and Autophagic Pathologies between Infants and Adults with Pompe Disease: Implications for Therapy. Molecular Genetics and Metabolism, 101, 324-331.

https://doi.org/10.1016/j.ymgme.2010.08.001

[5] Raval, K.K., Tao, R., White, B.E., et al. (2015) Pompe Disease Results in a Golgi-based Glycosylation Deficit Human Induced Pluripotent Stem Cell-Derived Cardiomyocytes. The Journal of Biological Chemistry, 290, 3121-3136.

https://doi.org/10.1074/jbc.M114.628628

[6] Kishnani, P.S., Goldenberg, P.C., DeArmey, S.L., Heller, J., Benjamin, D., Young, S., et al. (2010) Cross-Reactive Immunologic Material Status Affects Treatment Outcomes in Pompe Disease Infants. Molecular Genetics and Metabolism, 99, 26-33. https://doi.org/10.1016/j.ymgme.2009.08.003

[7] Kishnani, P.S., Steiner, R.D., Bali, D., Berger, K., Byrne, B.J., Case, L.E., The ACMG Work Group on Management of Pompe Disease, et al. (2006) Pompe Disease Diagnosis and Management Guidelines. Genetics in Medicine, 8, 267-288. https://doi.org/10.1097/01.gim.0000218152.87434.f3

[8] Howell, R.R., Byrne, B., Darras, B.T., Kishnani, P.S., Nicolino, M. and van der Ploeg, A.T. (2006) Diagnostic Challenges for Pompe Disease: An Underrecognized Cause of Floppy Baby Syndrome. Genetics in Medicine, 8, 289-296. https://doi.org/10.1097/01.gim.0000204462.42910.b8

[9] Llerena Junior, J.C., Horovitz, D.M., Marie, S.K.N., Porta, G., Giugliani, R., Rojas, M.V.M., et al. (2009) The Brazilian Consensus on the Management of Pompe Disease. Journal of Pediatrics, 155, S47-S56. https://doi.org/10.1016/j.jpeds.2009.07.006

[10] Llerena Junior, J.C., Nascimento, O.J.M., Oliveira, A.S.B., Dourado Junior, M.E.T., 
Marrone, C.D., Siqueira, H.H., et al. (2015) Guidelines for the Diagnosis, Treatment and Clinical Monitoring of Patients with Juvenile and Adult Pompe Disease. Arquivos de Neuro-Psiquiatria, 74, 166-176.

[11] Prater, S.N., Banugaria, S.G., De Armey, S.M., Botha, E.G., Case, L.E., Jones, H.N., et al. (2012) The Emerging Phenotype of Long-Term Survivors with Infantile Pompe Disease. Genetics in Medicine, 14, 800-810. https://doi.org/10.1038/gim.2012.44

[12] Case, L.E., Beckemeyer, A.A. and Kishnani, P.S. (2012) Infantile Pompe Disease on ERT-Update on Clinical Presentation, Musculoskeletal Management, and Exercise Considerations. American Journal of Medical Genetics, 160C, 69-79. https://doi.org/10.1002/ajmg.c.31321

[13] Ebbink, B.J., Poelman, E., Aarsen, F.K., Plug, I., Régal, L., Muentjes, C., Van Der Beek, N.A.M.E., MH, Van Der Ploeg, A.T. and Van Den Hout, J.M.P. (2018) Classic Infantile Pompe Patients Approaching Adulthood: A Cohort Study on Consequences for the Brain. Developmental Medicine \& Child Neurology, 60, 579-586. https://doi.org/10.1111/dmcn.13740

[14] Pereira, S.J., Berditchevisky, C.R. and Marie, S.K. (2008) Relato do primeiro paciente brasileiro com a forma infantil da doença de Pompe tratado com alfa-glicosidase recombinante humana. Jornal de Pediatria, 84, 272-275. https://doi.org/10.1590/S0021-75572008000300014

[15] Thomazinho, P.A., Scalco, F.B., Oliveira, M.L.C., Horovitz, D.D.G. and Llerena Jr., J.C. (2017) Motor Development as a Potential Marker to Monitor Infantile Pompe Disease on Enzyme Replacement Therapy. Open Journal of Clinical Diagnostics, 7, 8-19. https://doi.org/10.4236/ojcd.2017.71002

[16] Oba-Shinjo, S.M., da Silva, R., Andrade, F.G., et al. (2009) Pompe Disease in a Brazilian Series: Clinical and Molecular Analyses with Identification of Nine New $\mathrm{Mu}$ tations. Journal of Neurology, 256, 1881-1890. https://doi.org/10.1007/s00415-009-5219-y

[17] Mendelsohn, N.J., Messinger, Y.H., Rosenberg, A.S. and Kishnani, P.S. (2009) Elimination of Antibodies to Recombinant Enzyme in Pompe's Disease. The New England Journal of Medicine, 360, 194-195. https://doi.org/10.1056/NEJMc0806809

[18] Messinger, Y.H., Mendelsohn, N.J., Rhead, W., Dimmock, D., Hershkovitz, E., Champion, M., et al. (2012) Successful Immune Tolerance Induction to Enzyme Replacement Therapy in CRIM-Negative Infantile Pompe Disease. Genetics in Medicine, 14, 135-142. https://doi.org/10.1038/gim.2011.4

[19] Banugaria, S.G., Prater, S.N., Mackey, J., Das, S., Amalfitano, A., Rosenberg, A.S., et al. (2012) Persistence of High Sustained Antibodies to Enzyme Replacement Therapy Despite Extensive Immunomodulatory Therapy in an Infant with Pompe Disease: Need for Agents to Target Antibody-Secreting Plasma Cells. Molecular Genetics and Metabolism, 105, 677-680. https://doi.org/10.1016/j.ymgme.2012.01.019

[20] Yang, C.F., Yang, C.C., Liao, H.C., Huang, L.Y., Chiang, C.C., Ho, H.C., et al. (2016) Very Early Treatment for Infantile-Onset Pompe Disease Contributes to Better Outcomes. The Journal of Pediatrics, 169, 174-180. https://doi.org/10.1016/j.jpeds.2015.10.078

[21] Kamphoven, J.H., de Ruiter, M.M., Winkel, L.P., van den Hout, H.M., et al. (2004) Hearing Loss in Infantile Pompe's Disease and Determination of Underlying Pathology in the Knockout Mouse. Neurobiology of Disease, 16, 14-20. https://doi.org/10.1016/j.nbd.2003.12.018

[22] van Capelle, C.I., Goedegebure, A., Homans, N.C., Hoeve, H.L., Reuser, A.J. and 
van der Ploeg, A.T. (2010) Hearing Loss in Pompe Disease Revisited: Results from a Study of 24 Children. Journal of Inherited Metabolic Disease, 33, 597-602. https://doi.org/10.1007/s10545-010-9144-0

[23] Rohrbach, M., Klein, A., Kohli-Wiesner, A., et al. (2010) CRIM-Negative Infantile Pompe Disease: 42-Month Treatment Outcome. Journal of Inherited Metabolic Disease, 33, 751-757. https://doi.org/10.1007/s10545-010-9209-0

[24] Nicolino, M., Byrne, B., Wraith, J.E., Leslie, N., Mandel, H., Freyer, D.R., et al. (2009) Clinical Outcomes after Long-Term Treatment with Alglucosidase Alpha in Infants and Children with Advanced Pompe Disease. Genetics in Medicine, 11, 210-219. https://doi.org/10.1097/GIM.0b013e31819d0996

[25] van Gelder, C.M., Hoogeveen-Westerveld, M., Kroos, M.A., Plug, I., van der Ploeg, A.T. and Reuser, A.J. (2015) Enzyme Therapy and Immune Response in Relation to CRIM Status: The Dutch Experience in Classic Infantile Pompe Disease. Journal of Inherited Metabolic Disease, 38, 305-314.

https://doi.org/10.1007/s10545-014-9707-6

[26] Hahn, A., Praetorius, S., Karabul, N., Diebel, J., Schmidt, D., Motz, R., et al. (2015) Outcome of Patients with Classical Infantile Pompe Disease Receiving Enzyme Replacement Therapy in Germany. JIMD Reports, 65-75.

[27] Broomfield, A., Fletcher, J., Davison, J., Finnegan, N., Fenton, M., Chikermane, A., et al. (2016) Response of 33 UK Patients with Infantile-Onset Pompe Disease to Enzyme Replacement Therapy. Journal of Inherited Metabolic Disease, 39, 261-271. https://doi.org/10.1007/s10545-015-9898-5

[28] Chakrapani, A., Vellodi, A., Robinson, P., Jones, S. and Wraith, J.E. (2010) Treatment of Infantile Pompe Disease with Alglucosidase Alpha: The UK Experience. Journal of Inherited Metabolic Disease, 33, 747-750. https://doi.org/10.1007/s10545-010-9206-3

[29] Parini, R., de Lorenzo, P., Dardis, A., Burlina, A., Cassio, A., Cavarzere, P., et al. (2018) Long Term Clinical History of an Italian Cohort of Infantile Onset Pompe Disease Treated with Enzyme Replacement Therapy. Orphanet Journal of Rare Diseases, 13, 32. https://doi.org/10.1186/s13023-018-0771-0

[30] Al-Hassnan, Z.N., Khalifa, O.A., Bubshait, D.K., Tulbah, S., Alkorashy, M., Alzaidan, H., et al. (2018) The Phenotype, Genotype, and Outcome of Infantile-Onset Pompe Disease in 18 Saudi Patients. Molecular Genetics and Metabolism Reports, 15, 50-54. https://doi.org/10.1016/j.ymgmr.2018.02.001

[31] Kishnani, P.S., Corzo, D., Leslie, N.D., et al. (2009) Early Treatment with Alglucosidase Alpha Prolongs Long-Term Survival of Infants with Pompe Disease. Pediatric Research, 66, 329-335. https://doi.org/10.1203/PDR.0b013e3181b24e94

[32] Kishnani, P.S., Wuh-Liang, H., Mandel, H., Nicolino, M., Yong, F. and Corzo, D. (2006) A Retrospective Multinational, Multicenter Study of the Natural History of Infantile Pompe Disease. The Journal of Pediatrics, 148, 671-676. https://doi.org/10.1016/j.jpeds.2005.11.033

[33] Kroos, M., Hoogeveen-Westerveld, M., van der Ploeg, A. and Reuser, A.J. (2012) The Genotype-Phenotype Correlation in Pompe Disease. American Journal of Medical Genetics Part C: Seminars in Medical Genetics, 160, 59-68. https://doi.org/10.1002/ajmg.c.31318

[34] van den Berg, L.E., Drost, M.R., Schaart, G., de Laat, J., van Doorn, P.A., van der Ploeg, A.T. and Reuser, A.J. (2013) Muscle Fiber-Type Distribution, Fiber-Type Specific Damage, and the Pompe Disease Phenotype. Journal of Inherited Metabolic Disease, 36, 787-794. https://doi.org/10.1007/s10545-012-9541-7 
[35] Prater, S.N., Patel, T.T., Buckley, A.F., Mandel, H., Vlodavski, E., Banugaria, S.G., et al. (2013) Skeletal Muscle Pathology of Infantile Pompe Disease during Long-Term Enzyme Replacement Therapy. Orphanet Journal of Rare Diseases, 8, 90.

[36] Peng, S.S.F., Hwu, W.L., Lee, N.C., Tsai, F.K., Tsai, W.H. and Chien, Y.H. (2016) Slow, Progressive Myopathy in Neonatally Treated Patients with Infantile-Onset Pompe Disease: A Muscle Magnetic Resonance Imaging Study. Orphanet Journal of Rare Diseases, 11, 63. https://doi.org/10.1186/s13023-016-0446-7

[37] Wens, S.C.A., van Doeveren, T.E., Lequin, M.H., van Gelder, C.M., Verdijk, R.M., van der Hout, H.J., et al. (2015) Muscle MRI in Classic Infantile Pompe Disease. Journal of Rare Disorders. Diagnosis \& Therapy, 1, 10.

[38] Kroos, M., Hoogeveen-Westerveld, M., Michelakakis, H., Pomponio, R., van der Ploeg, A., Halley, D., Reuser, A.J., et al. (2012) Update of the Pompe Disease Mutation Database with 60 Novel GAA Sequence Variants and Additional Studies on the Functional Effect of 34 Previously Reported Variants. Human Mutation, 33, 1161-1165. https://doi.org/10.1002/humu.22108

[39] Cho, A., Kim, S.J., Lim, B.C., Hwang, H., Park, J.D., Kim, G.B., et al. (2012) Infantile Pompe Disease: Clinical and Genetic Characteristics with an Experience of Enzyme Replacement Therapy. Journal of Child Neurology, 27, 319-324. https://doi.org/10.1177/0883073811420295

[40] Pittis, M.G., Donnarumma, M., Montalvo, A.L., et al. (2008) Molecular and Functional Characterization of Eight Novel GAA Mutations in Italian Infants with Pompe Disease. Human Mutation, 29, E27-E36. https://doi.org/10.1002/humu.20753

[41] Montalvo, A.L., Bembi, B., Donnarumma, M., et al. (2006) Mutation Profile of the GAA Gene in 40 Italian Patients with Late-Onset Glycogen Storage Disease Type II. Human Mutation, 27, 999-1006. https://doi.org/10.1002/humu.20374

[42] Moravej, H., Karamizadeh, Z. and Paran, M. (2016) The Outcome of Infantile Onset Pompe Disease in South of Iran. Iran Journal of Pediatrics, 26, e4473. https://doi.org/10.5812/ijp.4473

[43] Pellegrini, N., Laforet, P., Orlikowski, D., et al. (2005) Respiratory Insufficiency and Limb Muscle Weakness in Adults with Pompe's Disease. European Respiratory Journal, 26, 1024-1031. https://doi.org/10.1183/09031936.05.00020005

[44] van der Beek, N.A., van Capelle, C.I., van der Velden-van Etten, K.I., Hop, W.C.J., van den Berg, B.W., Reuser, A.J.J., et al. (2011) Rate of Progression and Predictive Factors for Pulmonary Outcome in Children and Adults with Pompe Disease. Mo lecular Genetics and Metabolism, 104, 129-136. https://doi.org/10.1016/j.ymgme.2011.06.012

[45] van der Beek, N.A., de Vries, J.M., Hagemans, M.L., et al. (2012) Clinical Features and Predictors for Disease Natural Progression in Adults with Pompe Disease: A Nationwide Prospective Observational Study. Orphanet Journal of Rare Diseases, 7, 88. https://doi.org/10.1186/1750-1172-7-88

[46] Fuller, D.D., ElMallah, M.K., Smith, B.K., Corti, M., Lawson, L.A., Falk, D.J., et al. (2013) The Respiratory Neuromuscular System in Pompe Disease. Respiratory Physiology \& Neurobiology, 189, 241-249. https://doi.org/10.1016/j.resp.2013.06.007

[47] Sixel, B.S., Silva, L.D., Cavalcanti, N.C., Penque, G.M.C.A., Lisboa, S., Horovitz, D.D.G. and Llerena Jr., J.C. (2017) Manifestações respiratórias na doença de Pompe de início tardio: Uma série de casos no Brasil. The Jornal Brasileiro de Pneumologia, 43, 54-59. https://doi.org/10.1590/s1806-37562015000000343

[48] De Ruisseau, L.R., Fuller, D.D., Qiu, K., De Ruisseau, K.C., Donnelly, W.H. Jr., 
Mah, C., et al. (2009) Neural Deficits Contribute to Respiratory Insufficiency in Pompe Disease. Proceedings of the National Academy of Sciences, 106, 9419-9424. https://doi.org/10.1073/pnas.0902534106

[49] Falk, D.J., Todd, A.G., Lee, S., Soustek, M.S., ElMallah, M.K., Fuller, D.D., et al. (2015) Peripheral Nerve and Neuromuscular Junction Pathology in Pompe Disease. Human Molecular Genetics, 24, 625-636. https://doi.org/10.1093/hmg/ddu476

[50] Roberts, et al. (2011) The Prevalence and Impact of Scoliosis in Pompe Disease: Lessons Learned from the Pompe Registry. Molecular Genetics and Metabolism, 104, 574-582. https://doi.org/10.1016/j.ymgme.2011.08.011

[51] Khatwa, U.A. and Dy, F.J. (2015) Pulmonary Manifestations of Neuromuscular Diseases. Indian Journal of Pediatrics, 82, 841-851.

https://doi.org/10.1007/s12098-015-1814-3

[52] Hundsberger, T., Rösler, K.M. and Findling, O. (2014) Cessation and Resuming of Alglucosidase Alfa in Pompe Disease: A Retrospective Analysis. Journal of Neurology, 261, 1684-1690. https://doi.org/10.1007/s00415-014-7402-z

[53] Amartino, H.M. and Cavagnari, B.M. (2012) Enzyme Replacement Therapy in the Infantile Form of Pompe Disease: Argentinean Experience in a Seven-Year Follow-Up Case. Archivos Argentinos de Pediatria, 110, 323-327. https://doi.org/10.5546/aap.2012.323

[54] Fukuda, T., Ewan, L., Bauer, M., Mattaliano, R.J., Zaal, K., Ralston, E., Plotz, P.H. and Raben, N. (2006) Dysfunction of Endocytic and Autophagic Pathways in a Lysosomal Storage Disease. Annals of Neurology, 59, 700-708.

https://doi.org/10.1002/ana.20807

[55] van den Berg, L.E.M., Zandbergen, A.A., van Capelle, C.I., Vries, J.M., Hop, W.C., van den Hout, J.M., et al. (2010) Low Bone Mass in Pompe Disease-Muscular Strength as a Predictor of Bone Mineral Density. Bone, 47, 643-649. https://doi.org/10.1016/j.bone.2010.06.021

[56] Krishnamurthy, V.V., De Armey, S., Mackey, J., Frush, D., et al. (2005) Osteopenia in Infantile Pompe Disease: An Unrecognized Long-Term Complication. Molecular Genetics and Metabolism, 84, A227.

[57] Case, L.E., Hanna, R., Frush, D.P., Krishnamurthy, V., DeArmey, S., Mackey, J., et al. (2007) Fractures in Children with Pompe Disease: A Potential Long-Term Complication. Pediatric Radiology, 37, 437-445. https://doi.org/10.1007/s00247-007-0428-y

[58] Vialle, R., Thévenin-Lemoine, C. and Mary, P. (2013) Neuromuscular Scoliosis. Orthopaedics \& Traumatology: Surgery \& Research, 99S, S124-S139. https://doi.org/10.1016/j.otsr.2012.11.002

[59] Moreira, C.L.M. (2012) A Fisioterapia integrada a uma política pública em saúde: O estudo da funcionalidade de pacientes do Centro de Referência em Osteogênese Imperfeita do Rio de Janeiro. Tese de Doutorado, Pós-Graduação em Saúde da Criança e da Mulher, Instituto Nacional de Saúde da Mulher, da Criança e do Adolescente Fernandes Figueira, Rio de Janeiro.

[60] van Capelle, C.I., van der Meijden, C.J., van den Hout J.M.P., Jaeken, J., Baethmann, M., Voit, T., et al. (2016) Childhood Pompe Disease: Clinical Spectrum and Genotype in 31 Patients. Orphanet Journal of Rare Diseases, 11, 65. https://doi.org/10.1186/s13023-016-0442-y

[61] Spiridigliozzi, G.A., Keeling, L.A., Stefanescu, M., Li, C., Austin, S. and Kishnani, P.S. (2017) Cognitive and Academic Outcomes in Long-Term Survivors of Infantile-Onset Pompe Disease: A Longitudinal Follow-Up. Molecular Genetics and Me- 
tabolism, 121, 127-137. https://doi.org/10.1016/j.ymgme.2017.04.014

[62] Kishnani, P.S. and Beckemeyer, A.A. (2014) New Therapeutic Approaches for Pompe Disease: Enzyme Replacement Therapy and Beyond. Pediatric Endocrinology Reviews, 1, 114-124.

[63] Owens, P., Wong, M., Bhattacharya, K. and Ellaway, C. (2018) Infantile-Onset Pompe Disease: A Case Series Highlighting Early Clinical Features, Spectrum of Disease Severity and Treatment Response. Journal of Paediatrics and Child Health, 54, 1255-1261. https://doi.org/10.1111/jpc.14070

[64] Kishnani, P.S., Beckemeyer, A.A. and Mendelsohn, N.J. (2012) The New Era of Pompe Disease: Advances in the Detection, Understanding of the Phenotypic Spectrum, Pathophysiology, and Management. American Journal of Medical Genetics, 160C, 1-7. https://doi.org/10.1002/ajmg.c.31324

\section{Abbreviations}

CK Creatine kinase

CRIM Cross-reactiveimmunologic material

EF Ejection fraction

ERT Enzyme replacement therapy

FVC Forced vital capacity

GAA Acid $\alpha$-glucosidase

$\mathrm{Glc}_{4} \quad$ Glucose tetrasaccharide

GSD Glycogen storage disease

IOPD Infantile onset Pompe Disease

LV Left ventricle

LVMI Left ventricular mass index

MLPA Multiplex Ligand Probe Amplification

MM Muscles

rhGAA Recombinant human acid $\alpha$-glucosidase 